\title{
AVALIAÇÃO DO EFLUENTE DO DESSALINIZADOR E DA TILAPICULTURA EM SÃO JOSÉ DO SERIDÓ-RN
}

\author{
R. D. BEZERRA, M. B. VALE, J. A. S. GRILO JUNIOR* , C. C. M. BRAGA e J. K. S. OLIVEIRA \\ Instituto Federal de Educação, Ciência e Tecnologia do Rio Grande do Norte \\ jose.junior@ifrn.edu.br ${ }^{*}$
}

Artigo submetido em novembro/2015 e aceito em setembro/2016

DOI: $10.15628 /$ holos.2016.3643

\section{RESUMO}

A exploração das águas subterrâneas como forma de complementar e suprir a demanda de água na região do semiárido brasileiro, têm se tornado uma alternativa bastante utilizada pelo governo federal. Entretanto, devido aos altos teores de sais dissolvidos presentes nestas águas, a utilização de um tratamento para deixála potável é indispensável. O processo mais utilizado para este tratamento é o da dessalinização por osmose reversa, o qual produz certa quantidade de água potável e um rejeito bastante salino. Diversos estudos têm tentado encontrar uma alternativa para o aproveitamento deste efluente gerado, com o objetivo de minimizar o impacto ambiental. Uma forma de uso do efluente do dessalinizador é a sua aplicação em tanque de piscicultura, na qual a criação de tilápia tem apresentado um bom desempenho. Neste artigo buscou- se avaliar a qualidade do efluente da criação de tilápia na unidade demonstrativa da comunidade de Caatinga Grande no município de São José do Seridó - RN, com o uso de água proveniente de rejeito de dessalinizador. Para isso, foram medidos os parâmetros de condutividade elétrica, salinidade, cloreto, dureza da água do poço e do rejeito do dessalinizador. Buscou-se ainda quantificar os parâmetros físico-químicos do efluente da criação de tilápia, visando à aplicação na agricultura. Nesse sentido, os coliformes termotolerantes presentes no efluente da tilapicultura foram quantificados. O estudo é norteado pela lei no 6.938 , de 31 de agosto de 1981, a qual estabelece a Política Nacional do Meio Ambiente e define padrões de qualidade ambiental, e pelas resoluções no 357, 396 e 430 do CONAMA.

PALAVRAS-CHAVE: piscicultura, dessalinização, qualidade da água, efluente.

\section{STUDY OF WASTEWATER OF DESALINATOR AND TILAPIA CULTURE IN SÃO JOSÉ DO SERIDÓ-RN}

\begin{abstract}
The exploitation of groundwater for complement and meet the demand for water in the semiarid region of Brazil, has become an alternative often used by the federal government. However, due to the high contents of dissolved salts on the water, the use a treatment to make it drinkable is indispensable. The process most widely used for this treatment is the desalination by reverse osmosis, which produces a certain amount of water and a highly saline waste. Several studies have tried to find an alternative to the use of this effluent, with the goal of minimizing environmental impact. One way to use the effluent from desalination is its application in fish tank, in which the creation of tilapia has performed well. This study aimed to evaluate the effluent quality of tilapia
\end{abstract}

in the demonstration unit of the Caatinga Grande community in São José do Seridó - RN, using water from desalinator. For this, the parameters of electrical conductivity were measured, salinity, chloride, water hardness shaft and reject the desalinator. It has also sought to quantify the physicochemical parameters of the effluent of tilapia, aimed at application in agriculture. In this sense, thermotolerant coliforms present in the effluent of tilapia were quantified. The study is guided by the law No. 6938 of August 31, 1981, which establishes the National Environmental Policy and sets environmental quality standards, and the resolutions \# $357,396,430$ of CONAMA.

KEYWORDS: fish farming, desalination, water quality, effluent 


\section{INTRODUÇÃO}

A reutilização, reuso de água ou o uso de águas residuárias, não é um conceito novo e tem sido praticado em todo o mundo há muitos anos. Existem relatos de sua prática na Grécia Antiga, com a disposição de esgotos e sua utilização na irrigação. No entanto, a demanda crescente por água tem feito do reuso planejado da água um tema atual e de grande importância (SOUZA, 2014).

A região do semiárido brasileiro abrange a maior parte dos estados do Nordeste, e parte da região setentrional de Minas Gerais e o norte do Espírito Santo, abrangendo uma área total de $969.589,4 \mathrm{Km}^{2}$ (Cirilo, 2008). A precipitação pluviométrica é em média cerca de $750 \mathrm{~mm}$ ano-1, de forma bastante irregular no espaço e no tempo, embora em algumas áreas a precipitação média não ultrapasse os $400 \mathrm{~mm}^{2} \mathrm{ano}^{-1}$. E para agravar ainda mais, a evapotranspiração (perda de água pela evaporação), é bastante significativa chegando a $2.500 \mathrm{~mm} /$ ano, destacando o déficit hídrico como o maior obstáculo para a ocupação do semiárido, ocasionado a degradação da qualidade das águas por meio da eutrofização e salinização, dificultando assim a produtividade agrícola. Essas características climáticas, pedológicas e hidrológicas, constituem restrições para a utilização regular dos recursos hídricos, notadamente para o desenvolvimento da agricultura que, em razão do regime irregular de chuvas, depende da irrigação para o suprimento de água para as culturas. Com predominância da área localizada sobre formações do tipo cristalino, com solos pouco profundos e de baixa capacidade de infiltração e armazenamento, a ocorrência de águas subterrâneas nessas regiões está limitada a fraturas e fissuras nas rochas e a zonas de aluviões dos rios, formadas pela deposição de sedimentos fluviais. Há de se ressaltar, entretanto, a existência de bacias sedimentares, de ocorrência localizada, com grande potencial hídrico (INSA, 2012).

Três questões principais são abordadas sobre o desenvolvimento de aquicultura ambientalmente sustentável: o que aconteceu no passado, quais são as tendências de hoje, e o que pode o futuro? A tradicional aquicultura é maioritariamente compatível com o ambiente, pois utiliza na exploração e resíduos e subprodutos localmente disponíveis, tais como restos de culturas, animal ou estrumes ou alimento natural em corpos d'água abertos como insumos nutricionais para os organismos aquáticos cultivados. Já a moderna aquicultura é voltada para alimentos que serão agro-industrialmente transformados, embora também inclua tecnologias relativamente recentemente desenvolvidas, tais como a criação induzida por melhoramento genético, uso de hormônios e produtos químicos para diversos fins. Houve também um aumento rápido e relativamente recente na produção aquícola com base no desenvolvimento dessa aquicultura "moderna" através da aplicação da ciência e da tecnologia (EDWARDS, 2015).

No momento em que o país necessita gerar riquezas e trabalho, a curto e médio prazo, a piscicultura surge como uma possibilidade de transformar-se numa indústria que movimenta milhões de dólares em diversos países. O Brasil, no contexto internacional, insere-se com grande potencial para a piscicultura, pois além do seu território fluvial, conta com o favorecimento de suas condições climáticas para a criação de peixes de água doce. A produção de peixes no Brasil ainda apresenta resultados modestos de desenvolvimento, devido aos processos de produção adotados e à falta de informação sobre espécies nativas com potencial zootécnico (MÁRCIA GONÇALVES PIZAIA, 2008). 
Por sua vez, a tilápia é um peixe de origem africana, que vive em água doce. O seu cultivo tem se expandido rapidamente no mundo, ocupando, atualmente, o segundo lugar na produção de peixes de água doce cultivados. A primeira espécie que chegou ao Brasil foi a T. rendalli, na década de 1950.

A tilápia tornou-se um importante produto de aquicultura, em grande parte devido à sua adaptabilidade, que permite a rápida produção de peixes de tamanho comercial que atender às demandas do mercado (LOW et al., 2015). A tilápia é provável que seja o mais importante de todos os peixes de aquicultura no século 21 , sendo ela cultivada em pelo menos 85 países (SAYED; MONEEB, 2015).

As tilápias são peixes onívoros e rústicos, que se adaptam facilmente ao confinamento em sistemas intensivos de criação, tolerando baixos níveis de oxigênio e elevadas concentrações de amônia. Tais características também as levaram a ser cultivadas em águas salobras ou salgadas, trazendo ganhos econômicos, sociais e ambientais (ARAUJO et al., 2010).

De acordo com Porto (2000), dependendo do equipamento utilizado e da qualidade da água do poço, a quantia de rejeito originado varia entre 40 a $60 \%$ do volume total de água salobra oriunda do poço. De acordo com Paulino et al (2003), a criação de peixes em viveiros depende especialmente da qualidade da água do cultivo, e as variáveis que afetam sua qualidade são complexas e inconstantes, sendo necessário o aperfeiçoamento dos conhecimentos limnológicos do sistema. Dessa forma o presente trabalho tem por objetivo, avaliar a qualidade do efluente da criação de tilápia na unidade demonstrativa da comunidade de Caatinga Grande no município de São José do Seridó - RN.

\section{MATERIAIS E MÉTODOS}

A pesquisa foi desenvolvida na Unidade Demonstrativa do Assentamento "Caatinga Grande", distante 8 km da Sede do município de São José do Seridó - RN (6²6'57" S; 36 52'40" W), conforme a Figura 1. O Assentamento encontra-se localizado numa chapada, com cerca de 2.000 hectares de extensão, onde moram 73 famílias que vivem das atividades de agricultura e pecuária. Esta comunidade é constituída de assentados da reforma agrária, na qual cada família recebeu do governo federal 20 hectares de terra para o desenvolvimento de atividades agropecuárias.

O município está localizado na microrregião do Seridó Oriental, limitando-se com os municípios de Cruzeta, Caicó, Jardim do Seridó e Acari, situando-se a 207 m de altitude, numa área de $174,50 \mathrm{~km}^{2}$, equivalente a $0,35 \%$ da superfície do Rio Grande do Norte e tendo como base econômica a agropecuária e extração mineral (IDEMA, 2008). Geologicamente o município abrange terrenos pertencentes ao Embasamento Cristalino, com rochas da Formação Seridó da idade Pré-Cambriano, 579 milhões de anos caracterizada por biotita xisto, sericita xisto, filitos e calcários. O solo é Bruno não Cálcio, Sílico-Argiloso e Pedregoso (CPRM, 2005).

O clima da região apresenta precipitação anual média de $896,3 \mathrm{~mm}$, com chuvas escassas e mal distribuídas durante o ano inteiro, pois o período chuvoso geralmente é de no máximo três meses no ano. A umidade relativa do ar média de 62\% anual. Evapotranspiração média de 1.500 $\mathrm{mm}$ anuais, temperatura média do ar dos últimos trinta anos de $26,8 \stackrel{\circ}{ } \mathrm{C}$. A classificação do clima, 
Segundo a classificação climática de Köppen, adaptada ao Brasil, o clima de São José do Seridó é do tipo Bsh - Tropical Semiárido (CPRM, 2005).

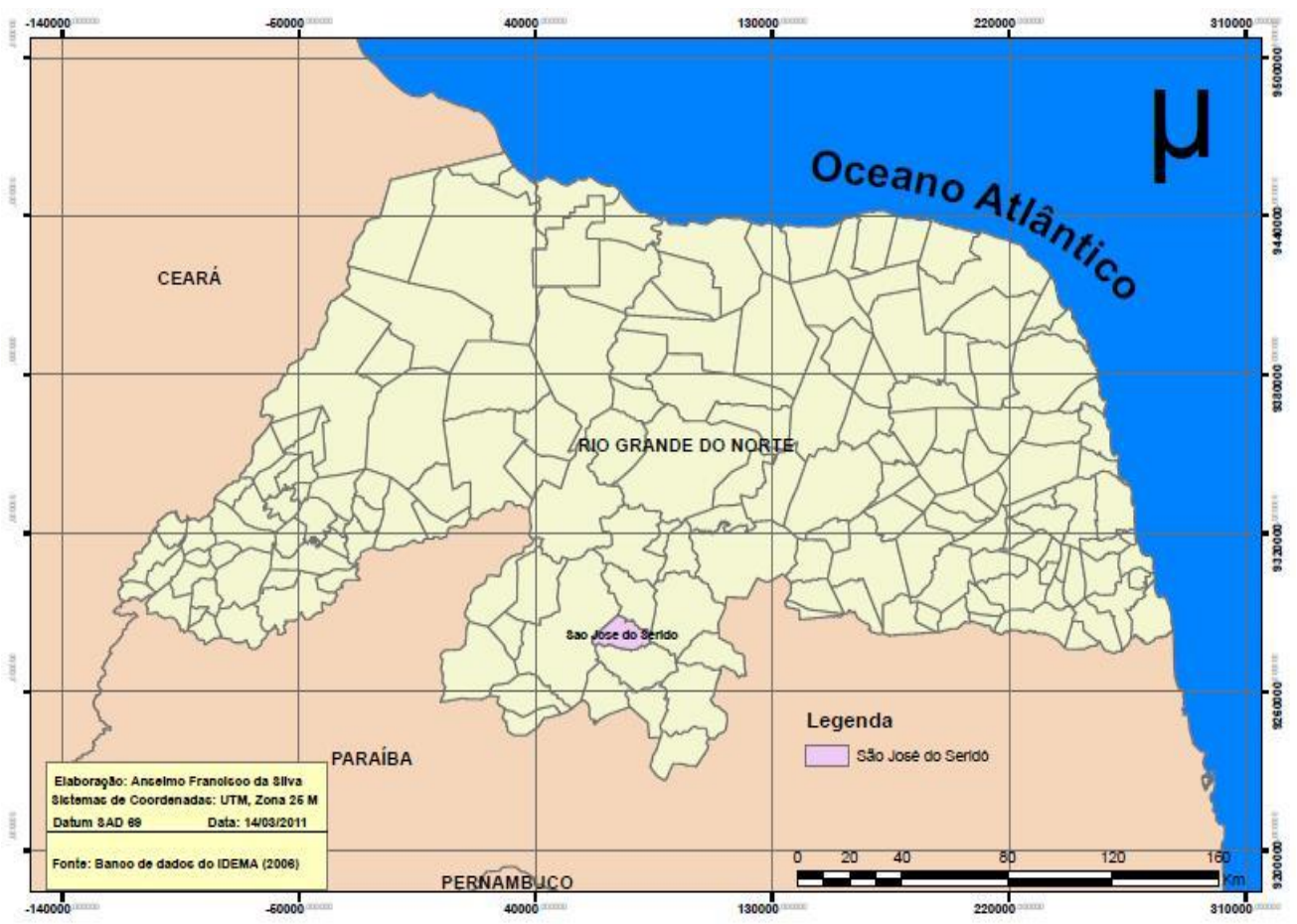

Figura 1: Mapa do Rio Grande do Norte, com a localização da unidade demonstrativa (UD) do Assentamento "Caatinga Grande", no município de São José do Seridó-RN.

Os experimentos foram realizados em campo na Unidade Demonstrativa (UD) da comunidade "Caatinga Grande" em São José do Seridó/RN. A UD foi implantada pela Embrapa junto com outras entidades em 2006. É um sistema constituído de três unidades integradas, a primeira é o dessalinizador que abastece a comunidade com água potável cujo poço tem vazão de $5.000 \mathrm{~L} / \mathrm{h}$ (Figura 2).

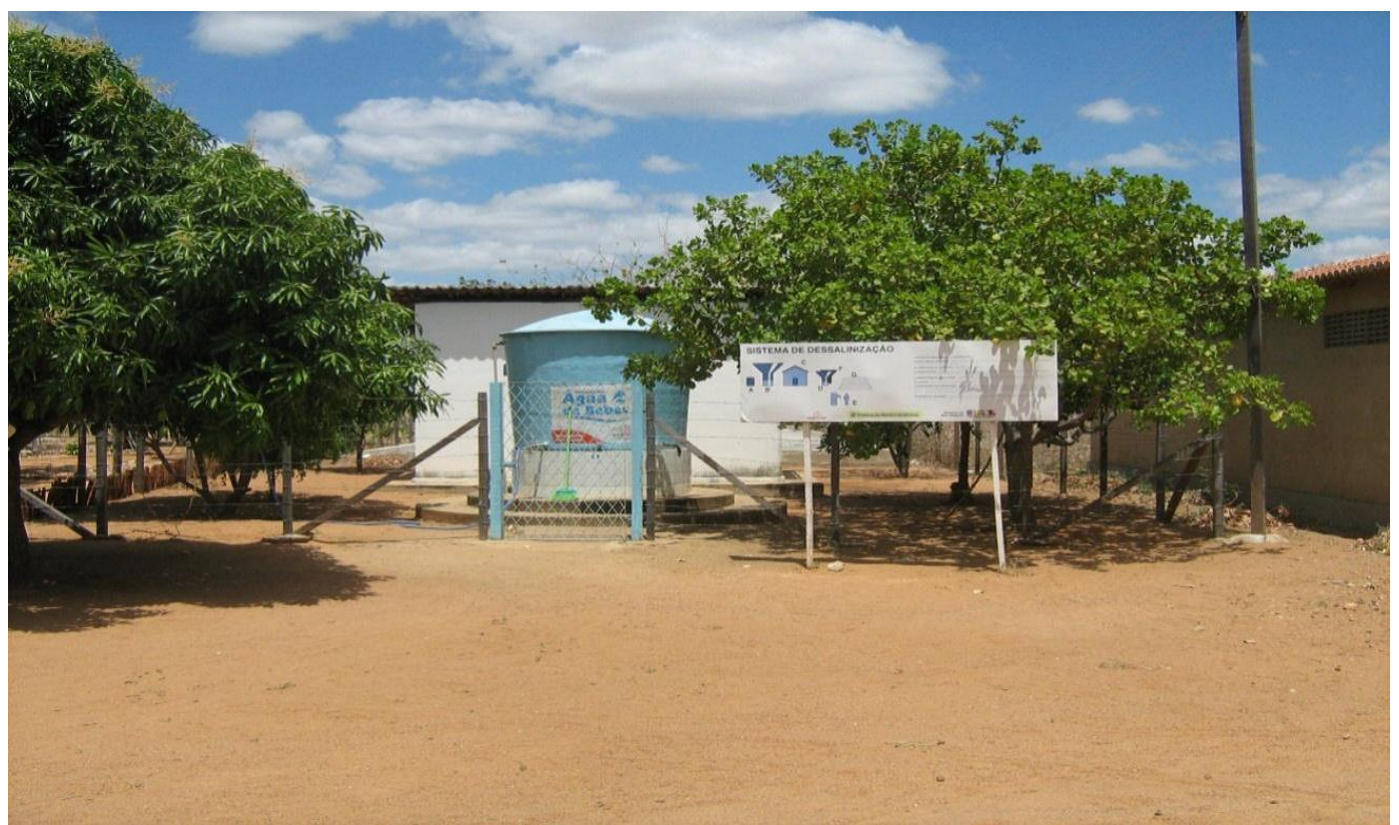

Figura 2: Usina de dessalinização com reservatório de água potável de $5 \mathrm{~m}^{3}$ da unidade demonstrativa (UD) do Assentamento “Caatinga Grande”, no município de São José do Seridó-RN. 
O dessalinizador de água funciona de três a cinco vezes por semana no período da manhã das 7 às 10 horas com produção em média de $15 \mathrm{~m}^{3}$ por semana. A segunda unidade é a de produção aquícola, formada pelo conjunto de três tanques com capacidade média de $350 \mathrm{~m}^{3} \mathrm{cada}$, implantados no solo revestidos com mantas de PVC de $0,8 \mathrm{~mm}$ de espessura resistentes à ação dos raios ultravioletas, sendo dois deles destinados exclusivamente ao cultivo da tilápia (Figura 3), e os mesmo constam de filtros na saída das tubulações de passagem para que os peixes não escapem dos tanques de cultivo e como também partículas maiores como restos de ração peletilizada. Cada tanque possui um aerador. $O$ terceiro tanque é o de acumulação dos efluentes gerados nos dois tanques da piscicultura (Figura 4), cuja água residuária é destinada à irrigação. A renovação de água dos tanques é realizada quinzenalmente com $30 \%$ de cada viveiro de forma alternada, com aeração parcial nos viveiros das $17 \mathrm{~h}$ às $19 \mathrm{~h}$.

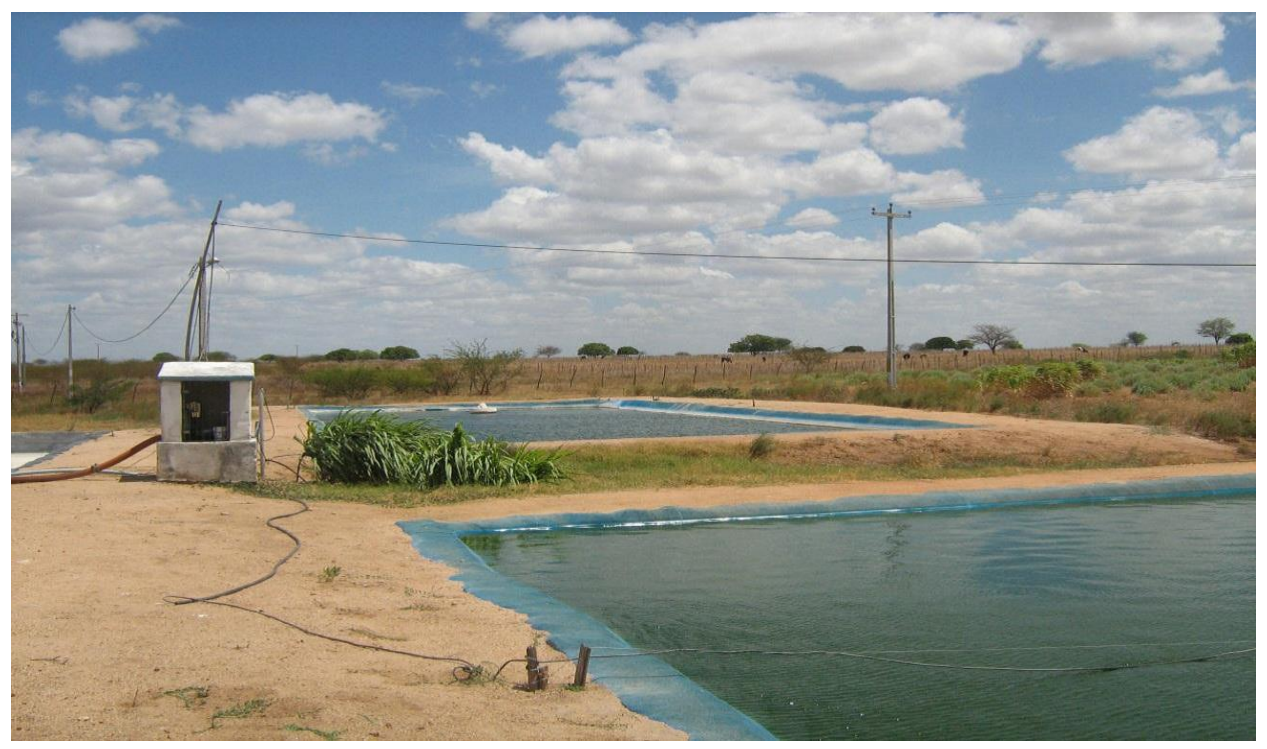

Figura 3: Tanques de piscicultura com revestimento plástico da unidade demonstrativa (UD) do Assentamento "Caatinga Grande", no município de São José do Seridó-RN.

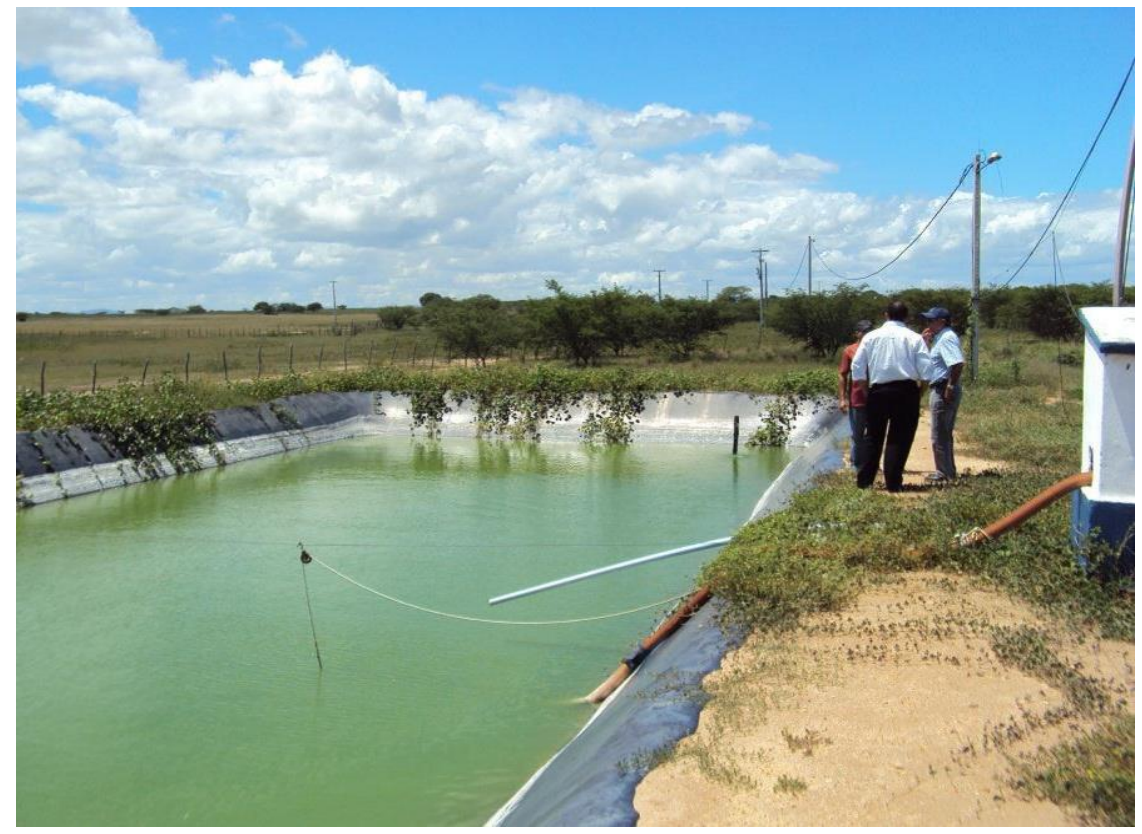

Figura 4: Tanque de acumulação dos efluentes da piscicultura da unidade demonstrativa (UD) do Assentamento "Caatinga Grande", no município de São José do Seridó-RN. 
A terceira unidade é a produção agrícola através cultivo de Atriplex nummularia (erva-sal) (Figura 5). A cultura é irrigada pelo sistema de gotejamento nas 776 plantas colocadas num espaçamento $3 \mathrm{~m}$ entre linhas por $3 \mathrm{~m}$ entre plantas, que por sua vez a atriplex é dado diretamente aos animais ou utilizado na produção de feno.

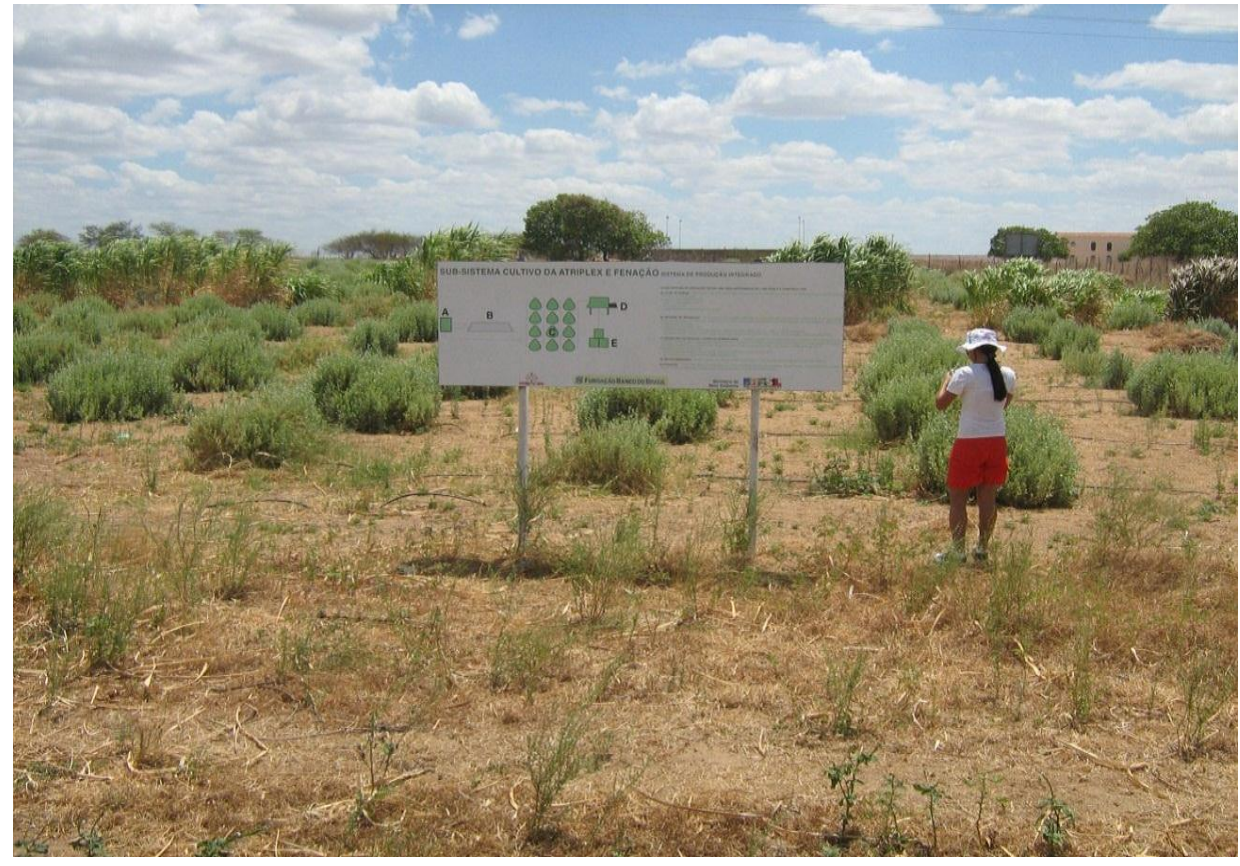

Figura 5: Área de cultivo de Atriplex nummularia irrigada da unidade demonstrativa (UD) do Assentamento "Caatinga Grande", no município de São José do Seridó-RN.

Assim, os componentes que constituem a Unidade Demonstrativa de São José do Seridó estão representados na Figura 6.

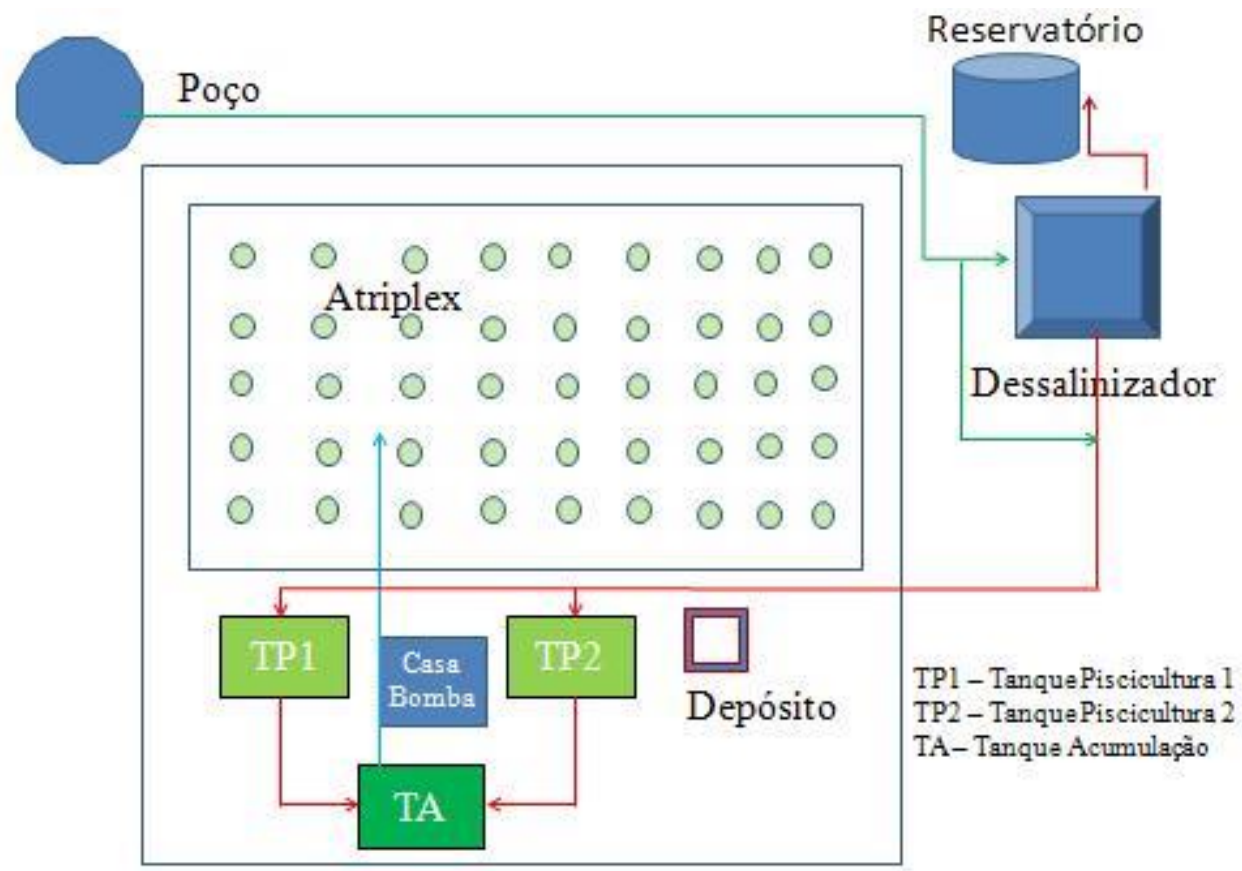

Figura 6: Esquema de distribuição dos componentes e funcionamento da unidade demonstrativa (UD) do Assentamento "Caatinga Grande", no município de São José do Seridó-RN. 
Como o sistema aquícola utilizam as águas provenientes do rejeito do dessalinizador e do poço tubular com vazão de $5 \mathrm{~m} 3 / \mathrm{h}$, foram realizadas três coletas de amostras de águas: o primeiro no rejeito do dessalinizador, o segundo no poço e o terceiro do tanque de acumulação que recebe os efluentes dos dois tanques de tilapicultura. Os dados de qualidade de água foram coletados entre 11 e 12 horas. No tanque de acumulação, a amostra foi retirada a $20 \mathrm{~cm}$ de profundidade com o auxílio de garrafa tipo Van Dorn, enquanto no dessalinizador e no poço foram coletadas diretamente da tubulação.

As amostras líquidas foram coletadas em frascos apropriados com capacidade de dois litros, em seguida, esses frascos foram mantidos acondicionados em recipiente térmicos, e transportados à temperatura refrigerada ao laboratório de Recursos Naturais do Instituto Federal de Ciência e Tecnologia do Rio Grande do Norte (IFRN), em Natal-RN, onde imediatamente se iniciaram os ensaios analíticos. O sistema foi monitorado no período de três meses, através de três coletas, realizadas nos dias 01/12/2011, 22/12/2011 e 09/02/2012.

As análises das fontes de abastecimento visou conhecer as características químicas e físicas para identificar a fonte de água de abastecimento, enquanto a análise dos efluentes da piscicultura teve o objetivo de identificar constituintes químicos capazes de complementar ou substituir a adição de fertilizantes químicos no solo, e o risco ambiental com uso de irrigação com água salina da criação de tilápia. Os parâmetros físico-químicos e microbiológicos que foram determinados são os seguintes: temperatura, $\mathrm{pH}$, condutividade elétrica, alcalinidade total, dureza total, cálcio, magnésio, sódio, potássio, cloreto, carbonato, bicarbonato, sulfato, nitrogênio total, fósforo total, coliformes termotolerantes.

Os métodos analíticos utilizados para a caracterização das amostras seguiram os procedimentos descritos por APHA et al (2005) e estão determinados na tabela 1.

Tabela 1: Parâmetros analisados e respectivos métodos adotados no laboratório.

\begin{tabular}{c|c|c|c}
\hline Parâmetro & Método analítico NAAE & Parâmetro & Método analítico NAAE \\
\hline Alcalinidade & $\mathrm{SM} / 2320 \mathrm{~B}$ & Dureza Total & $\mathrm{SM} / 2340 \mathrm{C}$ \\
Cálcio & $\mathrm{SM} / 3500 \mathrm{~B}$ & Ortofosfato Solúvel & $\mathrm{SM} / 4500 \mathrm{P}$ \\
Cloreto & $\mathrm{SM} / 4500 \mathrm{~B}$ & $\mathrm{STD}$ & $\mathrm{SM} / 2540 \mathrm{C}$ \\
Condutividade & $\mathrm{SM} / 2510 \mathrm{~B}$ & Nitrato $/ 4500 \mathrm{~B}$ \\
zSulfato & $\mathrm{SM} / 4500 \mathrm{E}$ & Nitrito & $\mathrm{SM} / 4500 \mathrm{~B}$ \\
Magnesio & $\mathrm{SM} / 3500 \mathrm{~B}$ & Amônia & $\mathrm{SM} / 4500 \mathrm{~B}$ \\
pH & $\mathrm{SM} / 4500 \mathrm{~B}$ & Ferro dissolvido & $\mathrm{SM} 500 \mathrm{~B}$ \\
Potássio & $\mathrm{SM} / 3500 \mathrm{~B}$ & Carbonato & $\mathrm{SM} / 3500 \mathrm{~B}-$ Titulometria \\
Sódio & $\mathrm{SM} / 3500 \mathrm{~B}$ & Bicarbonato & $\mathrm{SM} / 3500 \mathrm{~B}-$ Titulometria \\
Coliformes & $\mathrm{SM} / 9221$ & & - \\
Termotolerantes & & & \\
\hline
\end{tabular}

\section{$3 \quad$ RESULTADOS E DISCUSSÕES}

Foi avaliada a qualidade da água do poço e do rejeito do dessalinizador, e para isso utilizouse os parâmetros $\mathrm{pH}$, condutividade elétrica (CE), sólidos totais dissolvidos, dureza total, alcalinidade total e cloreto.

Os resultados estão representados na Tabela 2. 
Tabela 2: Resultados físico-químicos das amostras do poço e do rejeito.

\begin{tabular}{|c|c|c|c|}
\hline Parâmetros & UND & $\begin{array}{c}\text { POÇO } \\
\text { (MÉDIA) }\end{array}$ & $\begin{array}{l}\text { REJEITO } \\
\text { (MÉDIA) }\end{array}$ \\
\hline pH & ND & 7,75 & 7,80 \\
\hline Condutividade elétrica & $\mu \mathrm{S} / \mathrm{cm}$ & $6.309,20$ & $7.129,20$ \\
\hline $\begin{array}{l}\text { Sólidos Totais } \\
\text { Dissolvidos }\end{array}$ & $\mathrm{mg} / \mathrm{L}$ & $4.799,10$ & $5.058,33$ \\
\hline Dureza total & $\mathrm{mg} / \mathrm{L} \mathrm{CaCO}_{3}$ & 2525,10 & 2725,20 \\
\hline Alcalinidade Total & $\mathrm{mg} / \mathrm{L} \mathrm{CaCO}_{3}$ & 63,15 & 67,20 \\
\hline Cloreto & $\mathrm{mg} / \mathrm{L} \mathrm{Cl}-$ & $2.586,30$ & $2.611,28$ \\
\hline
\end{tabular}

Quanto ao parâmetro $\mathrm{pH}$ a média aritmética foi 7,75 e 7,80 para o poço e rejeito respectivamente. Observa-se que a variação é muito pequena, pois não houve a adição na água de nenhuma espécie química que influenciasse esse parâmetro.

Verificou-se que as concentrações de sais no rejeito do dessalinizador são maiores que a do poço, visto que o rendimento do processo de osmose reversa na obtenção de água potável é de aproximadamente $25 \%$. Essa comprovação foi rapidamente realizada, utilizando-se dos valores das condutividades elétricas das amostras, onde após a comparação dos resultados observou-se valores maiores para as amostras do rejeito do dessalinizador. Segundo Cosme (2011), os valores de condutividade elétrica das águas de rejeito são superiores aos das águas de poços proporcionados pelo aumento nas concentrações dos sais contidos na água residuária do processo de dessalinização. Observando os valores analíticos do STD, dureza total, alcalinidade total e cloreto ficam comprovados que há uma concentração de sais no rejeito da dessalinização.

Os valores da dureza total das amostras são justificados pela formação rochosa onde se encontra essa fonte de recurso hídrico e pelos elevados teores de cátions na água, principalmente de cálcio e magnésio.

Tabela 3: Valores de referência da água para consumo humano e águas subterrâneas.

\begin{tabular}{|c|c|c|c|c|c|}
\hline Parâmetro & Unidade & $\begin{array}{c}\text { POÇO } \\
\text { (MÉDIA) }\end{array}$ & $\begin{array}{l}\text { REJEITO } \\
\text { (MÉDIA) }\end{array}$ & $\begin{array}{l}\text { PORTARIA MS No } 2.941 \\
\text { (VALOR MÁXIMO } \\
\text { PERMITIDO }{ }^{(1)} \text { ) }\end{array}$ & $\begin{array}{l}\text { CONAMA No } 396 \\
\text { (VALOR MÁXIMO } \\
\text { PERMITIDO }{ }^{(2)} \text { ) }\end{array}$ \\
\hline $\mathrm{pH}$ & ND & 7,75 & 7,80 & $6,0-9,5$ & $6,0-9,5$ \\
\hline $\begin{array}{l}\text { Condutividade } \\
\text { elétrica }\end{array}$ & $\mu \mathrm{S} / \mathrm{cm}$ & $6.309,20$ & $7.129,20$ & ND & ND \\
\hline $\begin{array}{l}\text { Sólidos Totais } \\
\text { Dissolvidos }\end{array}$ & $\mathrm{mg} / \mathrm{L}$ & $4.799,10$ & $5.058,33$ & 1000 & 1000 \\
\hline Dureza total & $\mathrm{mg} / \mathrm{L} \mathrm{CaCO} 3$ & 2525,10 & 2725,20 & 500 & ND \\
\hline $\begin{array}{c}\text { Alcalinidade } \\
\text { Total }\end{array}$ & $\mathrm{mg} / \mathrm{L} \mathrm{CaCO} 3$ & 63,15 & 67,20 & ND & ND \\
\hline Cloreto & $\mathrm{mg} / \mathrm{L} \mathrm{Cl}-$ & $2.586,30$ & $2.611,28$ & 250,00 & 250,00 \\
\hline
\end{tabular}

(1) - Padrões de qualidade para consumo humano, segundo a Portaria 2.941 MS, de 12/12/2011.

(2) - Padrões de qualidade para água subterrânea com a finalidade de dessedentação de animais, segundo a Resolução CONAMA no 396, de 03/04/2008.

Em relação ao uso direto para o consumo humano, a água do poço e do rejeito da dessalinização são consideradas impróprias para o consumo humano por apresentar um elevado teor de sais, segundo a Portaria MS № 2.941/2011. 
O aproveitamento na dessedentação de animais conforme a Resolução CONAMA № 396 não é aceitável (tabela 3) e esta fonte de água subterrânea enquadra-se na classe II desta norma, que são águas dos aquíferos, sem alteração de sua qualidade por atividades antrópicas, e que podem exigir tratamento adequado, dependendo do uso preponderante, devido às suas características hidrogeoquímicas naturais.

Tabela 4: Classificação da água de irrigação pelo critério da salinidade, segundo Richards (1954).

\begin{tabular}{c|c|c}
\hline \multicolumn{2}{c|}{ Richards (1954) } \\
\hline Classe de Salinidade & $\left(\mathbf{d S ~ \mathbf { ~ } ^ { - 1 } )}\right.$ & Risco de Salinidade \\
C1 & $<0,75$ & Baixo \\
C2 & $0,75-1,50$ & Médio \\
C3 & $1,50-3,00$ & Alto \\
C4 & $>3,00$ & Muito alto \\
C4 (POÇO) & 6,30 & Muito alto \\
C4 (REJEITO) & $\mathbf{7 , 1 0}$ & Muito alto \\
\hline
\end{tabular}

Os valores médios do parâmetro CE encontrados no poço e rejeito foram 6.309,20 $\mu \mathrm{S} / \mathrm{cm}$ e 7.129,20 $\mu \mathrm{S} / \mathrm{cm}$ respectivamente. Baseando-se na classificação da água para irrigação de acordo com Richards (1954), as amostras estudadas encontram-se na C4 que são águas com muita salinidade e não é apropriada para irrigação sob condições normais, porém pode ser usada ocasionalmente, em circunstâncias muito especiais e mesmo assim devem ser explorados com culturas altamente tolerantes aos sais.

As amostras apresentaram altos teores de cloretos, ultrapassando os limites permitidos pela Resolução CONAMA no 396 para uso preponderante na irrigação (tabela 3). Quanto aos critérios de toxicidade sugeridos por Ayers e Westcot (1999), as fontes encontram-se no T3 para o íon cloreto por apresentar teores muito elevados.

Tabela 5: Concentrações do cloreto em água e respectivos riscos de toxicidade às plantas.

\begin{tabular}{c|c|c|c}
\hline \multirow{2}{*}{ T } & \multicolumn{2}{|c|}{ Teor de sódio ou cloreto $\left(\mathrm{mmol} \mathrm{c} \mathrm{L}^{-1}\right)$} & \multirow{2}{*}{ Problemas } \\
\cline { 2 - 3 } T1 & Irrigação por superfície & Irrigação por aspersão & \\
T2 & $3-9$ & $<3$ & Nenhum problema \\
T3 & $3-9$ & $>3$ & Problema moderado \\
\hline T3 (POÇO) & $>9$ & - & Problema severo \\
T3 (REJEITO) & \multicolumn{2}{|c|}{$\mathbf{7 2 , 9 5}$} & Problema severo \\
\hline
\end{tabular}

Para a avaliação da qualidade do efluente da piscicultura, utilizou-se os parâmetros pH, temperatura, condutividade elétrica (CE), sólidos totais dissolvidos, dureza total, alcalinidade total, cloreto, nitrogênio amoniacal, nitrato, nitrito, cálcio, magnésio, sódio, potássio, carbonato, bicarbonato, sulfato, cloreto, coliformes termotolerantes e o cálculo da RAS.

Os resultados bacteriológicos representado pelos coliformes termotolerantes das três amostras do tanque de efluente, estão dispostos na Tabela 10 com o valor máximo para irrigação de água salobra classe 1 de acordo da Resolução CONAMA no 357, de 17/03/2005.

Tabela: 6 Resultados bacteriológicos das amostras do efluente.

\begin{tabular}{c|c|c|c}
\hline PARÂMETRO & UNIDADE & Média & Valor máximo $^{(1)}$ \\
\hline $\begin{array}{c}\text { Coliformes } \\
\text { termotolerantes }\end{array}$ & $\mathrm{NMP} / 100 \mathrm{~mL}$ & 230 & $200 / 100 \mathrm{~mL}$ \\
\hline
\end{tabular}

(1) - Padrões de qualidade para água salobra classe 1, de acordo da Resolução CONAMA no 357, de 17/03/2005. 
Verifica-se que a análise bacteriológica apresentou o valor médio geométrico de coliformes termotolerantes de $230 / 100 \mathrm{~mL}$ estando fora do limite máximo permitido pela resolução CONAMA № 357. A literatura relata que valores acima de $1.000 / 100 \mathrm{~mL}$ não são indicados para o cultivo de animais aquáticos

Os resultados físico-químicos obtidos com as análises das três amostras do efluente da piscicultura estão representados na Tabela $7 \mathrm{com}$ a média aritmética dos valores encontrados. Esta tabela também apresenta os valores máximos dos padrões de qualidade para água salobra classe 01, de acordo com a Resolução CONAMA no 357, de 17/03/2005 e os valores normais para água de irrigação, de acordo com Ayers \& Westcot (1976).

Tabela 7: Resultados físico-químicos das amostras do tanque de efluente.

\begin{tabular}{|c|c|c|c|c|}
\hline Parâmetro & Unidades & Média & Valor Máximo (1) & Intervalo usual (2) \\
\hline Condutividade elétrica & $\mu \mathrm{S} / \mathrm{cm}$ & $8.859,33$ & ND & 3.000 \\
\hline $\mathrm{pH}$ & ND & 7,8 & $5,0-9,0^{(3)}$ & $6,0-8,5$ \\
\hline Sólidos Totais Dissolvidos & $\mathrm{mg} / \mathrm{L}$ & $6.417,33$ & ND & $0-1000$ \\
\hline Alcalinidade total & $\mathrm{mg} / \mathrm{L} \mathrm{CaCO}_{3}$ & 96,6 & ND & ND \\
\hline Alcalinidade a hidróxidos & $\mathrm{mg} / \mathrm{L} \mathrm{CaCO}_{3}$ & 0 & ND & ND \\
\hline Alcalinidade a carbonatos & $\mathrm{mg} / \mathrm{L} \mathrm{CaCO}_{3}$ & 7,06 & ND & ND \\
\hline Alcalinidade a bicarbonatos & $\mathrm{mg} / \mathrm{L} \mathrm{CaCO}_{3}$ & 23,8 & ND & ND \\
\hline Dureza total & $\mathrm{mg} / \mathrm{L} \mathrm{CaCO}_{3}$ & $3.825,00$ & ND & ND \\
\hline Nitrogênio Amoniacal & $\mathrm{mg} / \mathrm{L} \mathrm{NH}_{3}$ & 4,04 & $0,40^{(1)}$ & $0-5$ \\
\hline Nitrato & $\mathrm{mg} / \mathrm{L} \mathrm{N}$ & 32,23 & $0,40^{(1)}$ & $0-10$ \\
\hline Nitrito & $\mathrm{mg} / \mathrm{L} \mathrm{N}$ & 1,04 & $0,07^{(1)}$ & ND \\
\hline Cálcio & $\mathrm{mg} / \mathrm{L} \mathrm{Ca}^{+2}$ & 700,4 & ND & $0-400,8$ \\
\hline Magnésio & $\mathrm{mg} / \mathrm{L} \mathrm{Mg}^{+2}$ & 508,11 & ND & $0-60,6$ \\
\hline Sódio & $\mathrm{mg} / \mathrm{L} \mathrm{Na}^{+}$ & 724,25 & ND & $0-919,6$ \\
\hline Potássio & $\mathrm{mg} / \mathrm{L} \mathrm{K}^{+}$ & 80,23 & ND & $0-2$ \\
\hline Ferro Dissolvido & $\mathrm{mg} / \mathrm{L} \mathrm{Fe}^{+2}$ & 0,1 & ND & ND \\
\hline Carbonato & $\mathrm{mg} / \mathrm{L} \mathrm{CO}_{3}^{-2}$ & 15,96 & ND & $0-3$ \\
\hline Bicarbonato & $\mathrm{mg} / \mathrm{L} \mathrm{HCO}_{3}^{-}$ & 85,4 & ND & $0-610,2$ \\
\hline Sulfato & $\mathrm{mg} / \mathrm{L} \mathrm{SO}_{4}^{-2}$ & 26,45 & ND & $0-960,6$ \\
\hline Cloreto & $\mathrm{mg} / \mathrm{L} \mathrm{Cl}^{-}$ & $3.860,91$ & ND & $0-1063,5$ \\
\hline Ortofosfato Solúvel & $\mathrm{mg} / \mathrm{LP}$ & 1,14 & ND & $0-2$ \\
\hline RAS & meq. $L^{-1}$ & 6,92 & ND & $0-15$ \\
\hline Temperatura & ${ }^{\circ} \mathrm{C}$ & 32,0 & ND & ND \\
\hline
\end{tabular}

(1) - Padrões de qualidade para água salobra classe 1, de acordo da Resolução CONAMA no 357, de 17/03/2005.

(2) - Intervalo normal na água de irrigação, de acordo com Ayers \& Westcot (1976).

(3) - De acordo com a Resolução CONAMA 430, de 13/05/2011.

ND - Não definido pelas normas.

Inicialmente através dos resultados das análises físico-químicas, observa-se que houve uma variabilidade entre os valores dos parâmetros analisados do rejeito da dessalinização e do efluente. 
Esta variação é justificada pela alta taxa de evaporação e pela introdução de ração no tanque da piscicultura.

A temperatura foi analisada in situ apresentando o valor médio de $32 \circ \mathrm{C}$ atendendo a Resolução Conama № 430, a qual dispõe sobre as condições e padrões de lançamento de efluentes.

$\mathrm{O}$ pH do efluente apresentou o valor médio de 7,80 estando dentro das condições de lançamento de efluentes segundo a Resolução CONAMA № 430, a qual determina que pH esteja entre 5 a 9.

O valor médio da condutividade elétrica foi de $8.859,33 \mu \mathrm{S} / \mathrm{cm}$. Castro et al. (2005), registraram valores maiores de condutividade elétrica no efluente do cultivo de peixes em relação à água do abastecimento. Este fato deve-se possivelmente à presença de um aporte maior de nutrientes na água. Tomando por referência a classificação da água para irrigação de acordo com Richards (1954), o efluente estudado assim como a água do poço e rejeito da dessalinização classifica-se como $\mathrm{C} 4$.

Os valores da dureza total e de alcalinidade total encontrados no efluente apresentaram os valores médios de 3.825,00 mg/L de $\mathrm{CaCO} 3$ e $96,60 \mathrm{mg} / \mathrm{L}$ de $\mathrm{CaCO} 3$ respectivamente. De acordo com Kubtiza (1998) a presença de íons Ca2+ e Mg2+ livres na água de cultivo (componentes maiores da dureza total) são de fundamental importância ao funcionamento do sistema tampão. Estes íons ajudam na imobilização dos íons $\mathrm{CO}=$ =, formando compostos menos solúveis, como os precipitados de $\mathrm{CaCO} 3$ e $\mathrm{MgCO} 3$. Deste modo, menos íons $\mathrm{CO} 3=$ estarão livres na água para se dissociar em HCO3- e $\mathrm{OH}$ - atenuando a elevação do pH da água, mesmo em períodos de intensa atividade fotossintética.

Em se tratando de padrões para lançamento de efluentes, a legislação vigente no país é omissa para os parâmetros dureza total, alcalinidade total, sulfato, carbonato e bicarbonato. Todavia, para o uso do efluente na agricultura, a dureza total é um parâmetro de interesse, pois

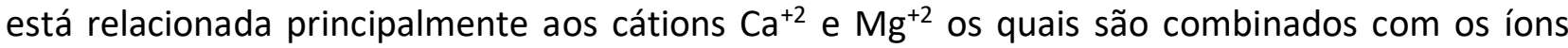
cloretos, sulfatos, nitratos, e indiretamente ao cálculo da RAS. Segundo Almeida (2010), águas muito duras são pouco recomendáveis em solos pesados e compactos, pois certos elementos têm efeitos tóxicos para os vegetais, principalmente os íons cloro e sódio, podendo causar toxicidade entre aqueles normalmente encontrados nas águas de irrigação.

O valor médio encontrado para o íon cloreto $\left(\mathrm{Cl}^{-}\right)$foi $3.860,91 \mathrm{mg} / \mathrm{L} \mathrm{Cl}^{-}$. A Resolução CONAMA № 430 não definiu para água salobra, o limite máximo permitido para lançamento dos íons $\mathrm{Cl}$ - no efluente. Para a agricultura, o teor médio encontrado ultrapassou o intervalo normal na água de irrigação, de acordo com Ayers \& Westcot (1976) tabela 7. Quanto aos critérios de toxicidade sugeridos por Ayers e Westcot (1999), o efluente classifica-se como T3 para o íon cloreto por apresentar teores muito elevados. Segundo Richards (1954), os principais íons de preocupação quanto à toxicidade são o cloreto, o sódio e o boro. Os problemas de toxicidade podem ocorrer mesmo quando estes íons estejam em baixas concentrações, pois o cloreto desloca-se facilmente com a água do solo e é absorvido pelas raízes.

O sulfato, carbonato e bicarbonato demonstraram valores médios de $26,45 \mathrm{mg} / \mathrm{L} \mathrm{SO}_{4}{ }^{-2}$, $15,96 \mathrm{mg} / \mathrm{L} \mathrm{CO}_{3}{ }^{-2}$, e $85,40 \mathrm{mg} / \mathrm{L} \mathrm{HCO}_{3}{ }^{-}$respectivamente. Para o uso na agricultura, o efluente 
atende ao intervalo normal para água de irrigação, de acordo com Ayers \& Westcot (1976) Tabela 11, exceto para o íon carbonato.

Os teores de amônia, nitrito e nitrato do tanque de efluente apresentaram valores médios de 4,04 mg/L NH $3,32,23 \mathrm{mg} / \mathrm{L} \mathrm{N}$ e 1,04 mg/L N respectivamente.

Os valores de amônia $\left(\mathrm{NH}_{3}\right)$ encontrados no efluente encontra-se dentro do limite máximo de lançamento de efluentes segundo a Resolução CONAMA № 430, que determina o valor máximo de $20,0 \mathrm{mg} / \mathrm{L} \mathrm{N}$. A diferença entre os teores de amônia do poço e do tanque de efluente é justificado pela liberação das excretas dos metabolismos do peixe e dos outros animais presentes no tanque de cultivo. O equilíbrio da amônia na água depende do $\mathrm{pH}$, da temperatura e da salinidade (QUEIROZ, 2007). De acordo com Kubtiza (2000) a amônia é proveniente da própria excreção nitrogenada dos peixes e da decomposição do material orgânico na água e está presente na água sob duas formas: o íon amônio $\mathrm{NH}_{4}{ }^{+}$(forma pouco tóxica) e a amônia NH3 (forma tóxica). Queiroz (2007) relata que o acúmulo de nitrogênio nos viveiros de aquicultura está diretamente relacionado com o manejo alimentar e com o percentual de nitrogênio contido na ração

Tabela 8: Concentração de amônia para lançamento de efluente em corpo aquático, valor ideal para a piscicultura e agricultura.

\begin{tabular}{|c|c|c|c|c|c|c|}
\hline \multirow{2}{*}{ Material } & \multirow{2}{*}{ UND } & \multirow{2}{*}{$\begin{array}{l}\text { EFLUENTE } \\
\text { (MEDIA) }\end{array}$} & \multirow{2}{*}{$\begin{array}{c}\text { CONAMA No } \\
430 \\
\text { (VALOR }^{\text {MÁXIMO }}{ }^{(1)} \text { ) }\end{array}$} & \multicolumn{2}{|c|}{ BOYD (1997) } & \multirow{2}{*}{$\begin{array}{c}\text { Intervalo } \\
\text { usual }^{(3)}\end{array}$} \\
\hline & & & & LETAL & SEGURO & \\
\hline $\begin{array}{l}\text { Nitrogênio } \\
\text { Amoniacal }\end{array}$ & $\begin{array}{c}\mathrm{mg} / \mathrm{L} \\
\mathrm{NH} 3\end{array}$ & 4,04 & 20,00 & $2-100$ & $<2$ & $0-5$ \\
\hline
\end{tabular}

O teor de amônia no efluente de acordo com a faixa de tolerância de Boyd (1997) é considerado letal para o crescimento do peixe, sendo este componente químico o principal estimulador da frequente renovação de água no tanque de piscicultura. Boyd (1997) enfatiza que o potencial poluidor dos viveiros de aquicultura aumenta em função do aumento na troca de água. Tanto do ponto de vista econômico quanto ambiental, a troca de água deve ser usada somente quando apresentar teores elevados de amônia.

O efluente apresentou o valor médio para o teor de ortofosfato solúvel de $1,14 \mathrm{mg} / \mathrm{L} \mathrm{P}$. O valor encontrado está fora do limite máximo para lançamento de água salobra classe $1(0,124 \mathrm{mg} / \mathrm{L}$ P), segundo a resolução CONAMA № 357. A presença deste composto no efluente deve-se a ração não consumida, a ação de microorganismos e excretas dos animais do viveiro.

O cálculo da RAS e da RASo do efluente demonstra o valor médio de 5,13 e 6,92 meq.L-1 respectivamente. Para água de irrigação no aspecto sodicidade de acordo com Richards (1954) o efluente classifica-se na classe S1. Com isso o efluente salobro ficou caracterizado segundo os critérios de Richards (1954) como C4S1 sendo considerada uma água não adequada para a agricultura.

\section{CONCLUSÃO}

As águas do poço e do rejeito da dessalinização possuem características físico-químicas bastante semelhantes, devido à baixa taxa de eficiência do aparelho de dessalinização a qual é de $25 \%$. 
Inicialmente a utilização do rejeito da dessalinização na piscicultura surgiu visando o uso múltiplo da água, através da inserção desta atividade produtiva com fins econômicos como forma de sustentabilidade ambiental. Entretanto, o volume de água necessário para abastecer os dois tanques de piscicultura é maior que o volume gerado.

Pelo rejeito da dessalinização, obrigando ao uso de mais água salobra do poço e como consequência uma maior quantidade de sais é lançado no meio ambiente. Dessa forma, o aproveitamento do rejeito para a criação de peixes cumpre o seu papel na busca por uma melhor eficiência hídrica, porém estimula o crescimento de efluente salino gerado no sistema, aumentando a insustentabilidade ambiental.

A legislação vigente no país preocupa-se em definir os padrões de lançamento de efluentes em corpos aquáticos, porém para o lançamento no solo ainda existe uma lacuna, a qual poderá ser posteriormente ocupada através de uma instrução normativa que incluam os limites máximos permitidos para disposição de efluente no solo.

Através dos resultados analíticos da $\mathrm{CE}$, cloreto, sódio e o cálculo da RASo comprovou-se que o efluente salobro é classificado como C4S1 e T3 para o íon cloreto, ou seja, a água é considerada muito ruim para a agricultura conforme a literatura consultada e poderá causar problemas de salinidade, sodicidade e toxicidade.

O efluente por ser rico em nutrientes como o potássio, nitrogênio e fósforo oriundo da água do poço, devido a outros fatores como as atividades metabólicas dos animais no tanque da piscicultura e da sobra de ração protéica que não foi totalmente ingerida pelos peixes, poderá ser utilizado na agricultura como substituição da fertilização, na forma de fertirrigação.

O lodo gerado nos viveiros é empregado como adubo na agricultura, pois contém nutrientes provenientes da água de cultivo.

A aplicação de técnicas de Boas Práticas de Manejo com o objetivo de reduzir a troca de água no tanque de piscicultura, observando o percentual de saciedade dos peixes e os teores de amônia e oxigênio dissolvido no viveiro é uma forma de minimizar o volume de efluente gerado.

\section{REFERÊNCIAS BIBLIOGRÁFICAS}

1. ARAUJO, Glacio Souza et al. CULTIVO DA TILÁPIA DO NILO EM TANQUES-REDE CIRCULARES EM DIFERENTES DENSIDADES DE ESTOCAGEM. Biosci. J, Uberlândia, p.428-434, 2010. Disponível em: $\quad$ <http://www.seer.ufu.br/index.php/biosciencejournal/article/viewFile/7080/4856>. Acesso em: 07 out. 2015.

2. AYERS, R. S., WESTCOT, D. W. A qualidade da água na agricultura. Disponível em: $<$ http://translate.google.com.br/translate?hl=pt-

BR\&sl=en\&tl=pt\&u=http\%3A\%2F\%2Fwww.fao.org\%2Fag\%2Fagl\%2Fpublic.stm>.

3. BARBOSA, Ana Célia Araújo; MOURA, Ezequias Viana de; SANTOS, Rafson Varela dos. CULTIVO DE TILÁPIAS EM GAIOLAS. Natal: Emparn, 2010. Disponível em: <http://adcon.rn.gov.br/ ACERVO/EMPARN/DOC/DOC000000000024667.PDF>. Acesso em: 09 out. 2015.

4. BOYD, C. E. Manejo do solo e da qualidade da água em viveiros de aquicultura. American Soybean Association, USA (Tradução Eduardo Ono), 1997, 55p.

5. BRASIL. Ministério do Meio Ambiente: Conselho Nacional do Meio Ambiente - CONAMA. 
Resolução no 357, de 17 de março de 2005. Classificação dos corpos de água e diretrizes ambientais para seu enquadramento, Brasília, DF.

6. BRASIL. Ministério do Meio Ambiente: Conselho Nacional do Meio Ambiente - CONAMA. Resolução no 430, de 13 de maio de 2011. condições e padrões de lançamento de efluentes, complementa e altera a Resolução no 357, de 17 de março de 2005, do Conselho Nacional do Meio Ambiente-CONAMA, Brasília, DF.

7. BRASIL. Ministério do Meio Ambiente: Conselho Nacional do Meio Ambiente - CONAMA. Resolução no 396, de 03 de abril de 2008. Classificação e diretrizes ambientais para o enquadramento das águas subterrâneas e dá outras providências, Brasília, DF.

8. BRASIL. Ministério da Saúde. MS. Portaria no 2.914, de 12 de dezembro de 2011. Procedimentos de controle e de vigilância da qualidade da água para consumo humano e seu padrão de potabilidade, Brasília, DF.

9. COSME, C. R. Avaliação da qualidade da água proveniente de estações de tratamento de água salobra na zona rural do município de Mossoró-RN. 2011.

10. CPRM. Projeto Cadastro de Fontes de Abastecimento por Água Subterrânea. Recife, 2005. Disponível em: <http://www.cprm.gov.br/rehi/atlas/rgnorte/relatorios/SJDS140.PDF> Acesso em 29 set. 2015.

11. EDWARDS, Peter. Aquaculture environment interactions: Past, present and likely future trends. Aquaculture, n. 447, p.2-14, 2015. Disponível em: <www.elsevier .com/locate/aquaonline>. Acesso em: 29 set. 2015.

12. IDEMA. Perfil do seu município. Natal, 2008. Disponível em:<http://www.idema.rn.gov.br/ contentproducao/aplicacao/idema/socio_economicos/arquivos/Perfil\%202008/S\%C3\%A30\% 20Jos\%C3\%A9\%20do\%20Serid\%C3\%B3.pdf> Acesso em 29 set. 2015.

13. Instituto Nacional do Semiárido. RECURSOS HÍDRICOS EM REGIÕES SEMIÁRIDAS: RECURSOS HÍDRICOS EM REGIÕES SEMIÁRIDAS. Campina Grande: Editoração Eletrônica, 2012. Disponível em: $\quad$ <http://www.insa.gov.br/wp-content/themes/insa_theme/acervo/recursos-hidricosII.pdf>. Acesso em: 23 set. 2015.

14. KUBITZA, F. 2000. Tilápias: água, cultivo, produção, nutrição e sanidade - Parte I. Revista Panorama da Aquicultura, Rio de Janeiro, 2000, p.44-53, mai/jun. Disponível em:<http://www.acquaimagem.com.br/docs/Pan59_Kubitza.pdf>Acesso em: 29 set. 2015.

15. KUBITZA, Fernando. Tilápia em água doce e salgada: Uma boa alternativa de cultivo para estuários e viveiros litorâneos. Panorama da Aquicultura, v. 15, n. 88, p.14-18, 2005. Disponível em: <http://web.uvic.ca/ soed/documents/Kubitza\%20Collection\%20II.pdf>. Acesso em: 26 out. 2015.

16. LOW, Kah Hin et al. Distribution and health risk assessment of trace metals in freshwater tilapia from three different aquaculture sites in Jelebu Region (Malaysia). Food Chemistry, n. 177, p.390-396, 2015. Disponível em: <www.elsevier.com/locate/foodchem>. Acesso em: 05 out. 2015.

17. MÁRCIA GONÇALVES PIZAIA, 46., 2008, Rio Branco. A PISCICULTURA NO BRASIL: UM ESTUDO SOBRE A PRODUÇÃO E COMERCIALIZAÇÃO DE "OREOCHROMIS NILOTICUS". Rio Branco: -, 2008. 16 p. Disponível em: <http://www.sober.org.br/palestra/9/497.pdf>. Acesso em: 29 set. 2015. 
18. PAULINO, Renata Vale. ARAÚJO, Odilon Juvino; PORTO, Everaldo Rocha. Cultivo de tilápia rosa (Oreochromis sp.) utilizando-se rejeito de dessalinização de água salobra subterrânea. XIII Congresso Brasileiro de Engenharia de Pesca, 2003, Porto Seguro. Anais... Porto Seguro: XIII CONBEP, 2003. p. 796-804.

19. QUEIROZ, J. F. de. Recomendações práticas para Melhorar a Qualidade da Água e dos Efluentes dos Viveiros de Aquicultura. Jaguariúna, EMPRABA. 2006.

20. RICHARDS, L.A. (ed.). Diagnosis and improvement of saline and alkali soils. Washington D.C.: U.S. Salinity Labratory., 1954. 160p. (USDA. Agriculture Handbook, 60). Disponível em http://naldc.nal.usda.gov/download/CAT87210573/PDF

21. SOUZA, Ana Cláudia Medeiros. MANEJO INTEGRADO DO REJEITO DA DESSALINIZAÇÃO DA ÁGUA SALOBRA NA AGRICULTURA. 2014. 47 f. Dissertação (Mestrado) - Curso de Gestão Ambiental, Departamento de Ciências Ambientais e Tecnológicas, Universidade Federal Rural do Semiárido, Mossoró, 2014. Disponível em: <http://ppgmsa.ufersa.edu.br/wpcontent/uploads/sites/59/2014/10/Dissertação-ANA-CLÁUDIA-MEDEIROS-SOUZA.pdf>. Acesso em: 23 set. 2015. 